\title{
Procesos de humanización de los perros de la ciudad de Xalapa
}

\author{
José Francisco Javier Kuri Camacho ${ }^{1}$
}

\begin{abstract}
RESUMEN
En el presente artículo se argumenta cómo los seres humanos han generado un proceso de humanización de los animales, especialmente con los perros. Los humanos cuando adquieren y cuidan un perro con sus prácticas diferenciales, demuestran protección, defensa, rechazo o indiferencia de manera desigual. Este tipo de prácticas diferenciales en los distintos sectores sociales ha provocado contradicciones sociales y culturales en la ciudad de Xalapa. Para ello, se revisa cómo en un barrio los humanos en su vida cotidiana tienen cierto tipo de prácticas hacia los caninos que deambulan por las calles, así como los que están encerrados en las casas, también se examina cuando transitan en ciertos territorios de la ciudad, hasta mostrar las representaciones sociales que se pueden dar en la ciudad de Xalapa sobre los procesos de humanización de éstos.
\end{abstract}

\begin{abstract}
In the present article it is argued how the human beings have generated a process of humanization of the animals, especially with the dogs. Humans, when they acquire and care for a dog with its differential practices, demonstrate unequal protection, defense, rejection or indifference. This type of differential practices in the different social sectors has provoked social and cultural contradictions in the city of Xalapa. For this, it is reviewed as in a neighborhood the humans in their daily life have certain types of practices towards the canines that roam the streets, as well as those that are locked in the houses, also is examined when they transit in certain territories of the city, To show the social representations that can be given in the city of Xalapa on the processes of humanization of these.
\end{abstract}

Palabras Clave: animales, humanismo, prácticas, subjetividad.

Keywords: animals, humanism, practices, subjectivity.

Introducción

$\amalg$ s sumamente interesante el proceso de humanización que se ha generado con los animales, especialmente con los perros, las maneras de percibir y realizar una serie de prácticas ha generado controversias que no sólo están en los medios de comunicación por un grupo defensores de los animales. Al llevar a cabo recorridos de observación desde febrero 2016 a marzo 2017, así como del diálogo con las personas de colonias como la Ferrer Guardia, la Obrero-Campesino e Indeco Ánimas, entre otras, es posible dar cuenta de que este proceso de humanización va adquiriendo una relevancia significativa en las prácticas humanas que van mostrando las diferencias sobre la protección, defensa, rechazo o indiferencia. Esto se advierte al reflexionar sobre cómo se debe concebir a los animales, los seres humanos y los espacios donde se desenvuelven.

El artículo se divide en tres apartados, primero se revisa una propuesta metodológica de Duhau y Gliglia (2008) para abordar el análisis

1 Instituto de Antropología.fkuri@uv.mx, jkuri2050@gmail.com. 
de la ciudad de Xalapa desde dos miradas: a) los sujetos que permanecen en el espacio local y, b) los sujetos que se mueven en la ciudad. Con estas dos consideraciones se podrá observar que las miradas aunque son diferenciales en su manera de percibir y actuar sobre los perros, siguen teniendo un punto común: la humanización de éstos.

El segundo apartado narra las prácticas de los humanos en el tratamiento de los animales desde el barrio y la ciudad, ya sea cuidándolos, aborreciéndolos o teniendo una actitud de indiferencia pero todos tienen una característica común, su mirada es desde del humanismo.

En el tercer apartado, se propone la construcción de una nueva mirada que contemple una percepción integral al considerar a los animales, los humanos, la tierra y la tecnología para que permita en nuestro hábitat, nuevas maneras de relacionarnos y por tanto, generar alternativas de convivencia práctica.

La ciudad de Xalapa y la materia fecal de los animales

La ciudad de Xalapa, Veracruz, es una ciudad media que, según el INEGI (Instituto Nacional de Estadística y Geografía), al 2015, tiene una población de 480,841 habitantes. Sus pobladores viven con una vegetación abundante aunque progresivamente se ha ido deteriorando. Todavía se puede observar, tocar y respirar los árboles, flores, pasto y yerba que crece en cualquier espacio que no se limite por la intervención humana. Es una ciudad cuya belleza se muestra a través de su naturaleza y que se distingue de otras ciudades del país porque no predominan las edificaciones coloniales de manera apabullante sobre la naturaleza.

Esto no significa que la ciudad de Xalapa no tenga problemas por atender, como en todas las ciudades del país, problemas ambientales, económicos, políticos, sociales, culturales y de educación, muchos de ellos han rebasado a las autoridades municipales, estatales y federales, uno de ellos, son las atenciones o descuidos con los animales lo que provoca un impacto ambiental, de salud y educativo.
De acuerdo a Nayeli Vera Brizuela (2017), coordinadora del Área de Salud del ayuntamiento de Xalapa, hay aproximadamente 60 mil perros y gatos en la ciudad, y de éstos, el 30 por ciento son animales callejeros, aunque las cifras pueden variar, lo cierto es que una población de animales con diferentes atenciones o descuidos por los seres humanos, se ha convertido en un problema de salud pública. De acuerdo con la prensa y confirmado por la citada coordinadora de salud, los perros callejeros todos los días dejan materia fecal, aunque hay que señalar que también los perros caseros cuando salen a la calle especialmente para que dejen las heces fecales sin que el humano se ocupe de levantar, por lo que se convierte en un problema de salud pública y de educación.

Amparo Martínez, Directora del Instituto Nacional de Ecología y Cambio Climático (INECC), expresa que: "Las bacterias que se liberan se unen a las partículas suspendidas, cuando las analizamos tienen pegados los elementos (de la materia fecal)." (Martínez como se citó en Zamarrón, 2017). Cuando la materia fecal se deja en la calle por los animales y no se levanta por los humanos, el sol la desintegra, con el viento se dispersa y se mezcla con otros componentes tóxicos, al respirar el polvo puede provocar enfermedades gastrointestinales, así como lesiones en los ojos, síntomas de gripe, úlceras y vómitos. Alejandra Vergara (2017), abordando el problema de la sobrepoblación canina en México, expresa lo siguiente:

Moscú, Bangkok, Deli y -lo sabemos bien- la Ciudad de México son otras ciudades que se enfrentan a un enorme número de perros callejeros y a los posibles riesgos sanitarios que estos implican. El más conocido de estos problemas es la rabia, ya que más del 90\% de los casos de esta enfermedad son debidos a mordidas de perros infectados. Sin embargo, hay más de sesenta enfermedades que pueden ser transmitidas a los humanos, afectando, principalmente, las mucosas y el sistema digestivo; la toxocariasis, que se transmite por parásitos en las heces de los perros, por ejemplo, puede causar fiebre, asma, e 
infecciones oculares que en casos severos pueden terminar en desprendimiento de la retina. En más de una ocasión se ha tratado de eliminar el problema matando a los perros. Independientemente de la cuestión ética, más que una solución esta medida es sólo un paliativo que no ataca a las causas del problema. Los perros callejeros tienen su origen en el abandono y la negligencia humana. Somos nosotros los que estamos creando un ambiente propicio para la reproducción descontrolada de perros que, dicho sea de paso, se enfrentan a una breve vida de hambre, lesiones y enfermedades. (p.1).

Esta situación que pareciera menor, tiene un problema de salud pública y de educación que tenemos que tratar. Cuando hay materia fecal esparcida en las calles pavimentadas libera bacterias lo que implica un problema de salud pública que es necesario atender y resolver por las enfermedades que provoca. Nayeli Vera, coordinadora del área de Salud del ayuntamiento de Xalapa, Veracruz, expresa que se tienen que dar alternativas de atención a los animales callejeros pues menciona que las personas adquieren mascotas como un regalo para sus hijos pero que una vez que crecen, son abandonados.

Por otra parte, la educación a la población es muy importante para dar un trato digno a los animales, ya que tener un animal no se reduce a proporcionar comida y sacarlo del encierro cuando se pueda. Las grandes empresas a través de los medios de comunicación han jugado un papel importante al manejar formas de representación sobre el trato y confort de los animales al venderles los alimentos y un sinfín de accesorios.

Lo que ofrecen los anuncios publicitarios es un guía de cómo deben tratar los humanos a sus mascotas, presentando una serie de productos que van desde alimentos hasta accesorios de todo tipo, como correas, ropa y peinados. También representan espacios de confort en sus hogares, escenificando casas que lucen con habitaciones limpias y con pasto para que el perro corra libremente. Todo ello converge en la idea de dotar de estos recursos para incorporar a los perros a la familia.

Por tanto, es fundamental la reeducación de los ciudadanos para generar un gran cambio cultural sobre cómo nos deberíamos de percibir y relacionarnos con los animales, la tierra, los árboles, el cemento, los autos y las edificaciones en la ciudad.

\section{Los animales en el barrio y la ciudad}

Hay dos maneras de abordar el análisis de los animales en el barrio y en la ciudad de Xalapa, especialmente los perros, ya que además de tener un problema de sobrepoblación también se han convertido en una pequeña muestra de disputa por humanizar a los perros, al defender, proteger, rechazar o ser indiferentes en determinados espacios.

Emilio Duhua y Ángela Giglia (2008), en su análisis de la experiencia urbana en la metrópoli, hay una distinción metodológica que para nuestros fines nos viene a bien. El primero, lo denominan espacio local o de proximidad y el segundo, espacio metropolitano. Con referencia al espacio local dicen: "En algunos casos, la experiencia del espacio local puede caracterizarse por permitir o favorecer una multiplicidad de relaciones sociales, que pueden constituir un tejido relativamente denso y así fortalecer el sentido de pertenencia y arraigo local." (p. 22), ya que su hábitat puede ser el barrio, la colonia, la unidad habitacional o un pueblo conurbado. Los actores sociales tienen mayor conocimiento y experiencia de este tipo de espacios, debido a que permanecen más tiempo y el uso y apropiación de su entorno le da sentido a su vida cotidiana.

Del mismo modo, en el espacio metropolitano también tiene múltiples relaciones pero el conocimiento de ciertos actores sociales depende y "responde a la lógica y a las estrategias de movilidad de los sujetos y a sus relaciones con la metrópoli", así como del tiempo que disponen para desplazarse de un punto a otro. Duhua y Giglia (2008, p.22), mencionan: "En este espacio, los sujetos dibujan sus relaciones en forma de telaraña, mucho menos densa, pero más 
amplia, en la que las distancias entre un punto y otro de la red pueden llegar a ser de varias decenas de kilómetros.. Este tipo de actores sociales pueden vivir en el barrio, en la colonia, en una unidad habitacional pero su tiempo y espacio está brindado a la metrópoli.

Estas dos formas de vivir el espacio urbano nos da señales de cómo los actores sociales en la ciudad de Xalapa pueden tratar a los animales durante la semana. Aquí, me concentraré en los actores sociales que viven en el barrio de San Bruno, ya que su radio de acción perimetral nuclea a colonias como Cerro Colorado, Los Pinos, Las Flores, Unidad Fovissste, Obrero Campesino y Ferrer Guardia, por un lado, y por el otro, en los habitantes que se mueven en la ciudad.

Prácticas humanas en el trato de los perros

Los habitantes que viven en el barrio, se caracterizan por establecer relaciones sociales intensas entre ellos y con el lugar donde residen. Mayol (2010, p. 9) lo define:

como el dominio en el cual la relación espacio/tiempo es la más favorable para un usuario que ahí se desplaza a pie a partir de su hábitat. Por consiguiente, es ese trozo de ciudad que atraviesa un límite que distingue el espacio privado del espacio público: es lo que resulta de un andar, de la sucesión de pasos sobre una calle, poco a poco expresada por su vínculo orgánico con la vivienda.

En el barrio de San Bruno, recrean su mundo con el trabajo doméstico, con el trabajo obrero y con los tiempos cortos de trabajo. En su vida cotidiana las mujeres, por las mañanas están dedicadas a las labores de la casa y una que otra aprovecha para salir a la venta de productos para la manutención de la familia. Otros se van a trabajar como hojalateros, taxistas, profesoras, policías o en las pequeñas empresas que poseen. Las tardes son el momento para descansar, los hombres lavan o componen su auto, las mujeres acompañan a su marido o simplemente salen a tomar el fresco, ante el calor que se ha sentido últimamente en la ciudad de Xalapa. Algunas más se reúnen para conversar sobre los sucesos más recientes del barrio. También hay momentos en que el silencio de sus habitantes y la soledad del barrio se hacen palpable, la televisión capta su atención.

Pero cualquier escenario que se exhiba durante las mañanas y las noches, los perros se hacen presentes con sus ladridos, sus movimientos ya sea solos o acompañados por alguna persona. Justamente cuando se muestra sus movimientos es cuando los seres humanos actúan de manera diferencial. Algunos los duermen en las casas, se suben a los sillones, los cargan, otros los dejan encerrados en la azotea, en la habitación o en el balcón hasta que lleguen en la tarde o en la noche, por lo que el animal tiende a ladrar por el aislamiento en que vive, sea porque se acabó el agua o algún alimento.

En cambio algunos perros callejeros, tienen libertad para desplazarse por algunas calles de la colonia, poco a poco van identificando el lugar donde pueden comer e incluso dormir. Los vecinos se compadecen de estas mascotas abandonadas proporcionándoles alimento, inclusive los acarician y comparten juegos con ellos.

No obstante su caridad hacia los perros esta ayuda es contraproducente, dado que rompe con la continuidad de su rutina. Por ejemplo, por las mañanas o las noches, los dueños de los perros conciben la calle como un espacio para que sus perros defequen, sin preocuparse por recoger el excremento que dejan sus mascotas ya que son parte de la familia, igualmente lo hacen los perros callejeros. Ignorar el grave problema de salud pública que ello provoca, es un grave problema social y de salud.

Recordemos que la materia fecal del animal se queda durante el día y combinado con el sol aparecen las moscas. Con el tiempo el sol desintegra esta materia fecal que es dispersada en forma de polvo por el viento, misma que afecta la salud de los humanos. Esta situación se puede resolver si se recogen estos residuos y se depositan en la basura. Hay que reconocer que algunos dueños que se preocupan por levantar 
las heces de sus mascotas en bolsas de plástico.

El ruido de los perros en la calle no siempre se debe a la presencia de un extraño, debemos indicar que en un barrio es necesario que las mascotas paseen y/o jueguen un rato para calmar su ansiedad, sin embargo en este escenario es común escuchar cómo se irritan los otros perros que ante su encierro buscan cómo relacionarse con los otros animales y los humanos.

Es sustancial mencionar que este fenómeno de presencia de los perros se incrementó en los últimos 5 o 10 años en el barrio, los vecinos se han preocupado por tener una mascota que les permita entretenerse, mostrar a un "buen perro", de raza, que se distinga de otros que los vecinos ya tienen, y sobre todo, de los de la calle. Un ejemplo de ello son las personas que tienen en sus casas cocheras que son utilizadas para tener un perro grande y de "buena" raza, diferenciándose de aquellas personas que rentan departamentos reducidos y que compran un perro pequeño que se distinga y los acompañe.

Por otro lado, los habitantes que se mueven por la ciudad y que residen en su colonia, barrio o unidad habitacional, no cuentan con el tiempo diario para dedicar atención a su perro, es hasta concluida la jornada laboral que llegan a su hogar por las tardes noches para atender las necesidades básicas de sus animales, confinándolos durante el día a la soledad y el encierro como parte de la vida cotidiana.

Los fines de semana se mezclan sin diferenciar la actividad humana con la canina, organizando sus salidas a espacios donde este permitido asistir con animales, así vemos los autos con un copiloto canino que disfruta del aire o bien, de pequeñas jaulas donde se transporta a las mascotas para que puedan acompañar en la comida con sus amos.

De acuerdo a los recorridos de observaciones realizados en colonias como Indeco Ánimas, Valle de las Ánimas y Vista Hermosa, se deduce que las prácticas diferenciales del trato a los animales adquieren características distintas de acuerdo a cada colonia, debido a los tipos de servicio o consumo que existen en torno al mundo de las mascotas, o al trato que comúnmente se les da a estos, cambiando las relaciones que se tienen con ellos. Algunos tienen la posibilidad de llevarlos a las estéticas caninas que empiezan a aparecer en la ciudad para mostrar la belleza de sus perros, lo bien cuidados que están y distinguirse por su esmero en el cuidado de pelo. Otros mientras tanto, destacan los gastos de atención de salud y alimentación de sus animales y en algunos solo mencionan el cuidado en su alimentación.

Este enjambre de prácticas está regulado no solo por las normas de los establecimientos y espacios libres, sino también por la sanción que efectúan los ciudadanos a los dueños de sus mascotas al asistir a ciertos espacios, por lo que, muchas de las veces se convierte en un problema llevarlos o no a sus paseos o compromisos sociales.

Estas prácticas se convierte en un símbolo de imagen y autoimagen, de estatus social y de pasarela para los humanos, en cambio las mascotas, estas deben aprender las prácticas humanas como un deber ser en sociedad.

\section{La construcción de una nueva mirada}

Tener una nueva mirada significa construir una nueva subjetividad. Esta nueva subjetividad es pensar en un marco epistémico diferente, no se puede seguir pensando que la tierra, los animales, la naturaleza, el universo, es a la medida del hombre. La separación milenaria naturaleza-cultura que hizo el hombre fue extraordinaria e impresionante, los mitos de la mayoría de los pueblos ya habían planteado la oposición naturaleza-cultura. (Levi-Strauss, 1985). El hombre a través de su acción transgredió de manera violenta el orden anterior. (San Martin, 1999). El hombre conoció que era capaz no sólo de transgredir y violentar sino también de controlar la naturaleza, saber que era capaz de eso y mucho más, vislumbró su avidez de conocer, controlar y transformar todo lo que estuviera a su alrededor. Horkheimer y Adorno (1997), explican: "Lo que los hombres quieren aprender de la naturaleza es la forma de utilizarla para lograr el dominio integral de la naturaleza y de los hombres." (p. 9). Pero no fue sólo el dominio y control de la naturaleza sino fue reducir la complejidad de esta última y el 
universo a la medida del hombre. Horkheimer y Adorno (1997), lo expresan así:

En la base del mito el iluminismo ha visto siempre antropomorfismo, la proyección de lo subjetivo sobre la naturaleza. Lo sobrenatural, espíritus y demonios, serían imágenes reflejas de los hombres, que se dejaban asustar por la naturaleza. Las diversas figuras míticas son todas reducibles, según el iluminismo, al mismo denominador, es decir, al sujeto. (...) El iluminismo reconoce a priori, como ser y acaecer, sólo aquello que se deja reducir a una unidad; su ideal es el sistema, del cual se deduce todo y cualquier cosa. En eso no se distinguen sus versiones racionalista y empirista. (p.10).

Esta concepción del hombre provocó rupturas: naturaleza-cultura, cuerpo y mente, sagrado-profano. Rupturas que con el proceso de urbanización y crecimiento de las ciudades en el siglo XIX y XX, no sólo transformaría el tiempo y el espacio sino también se pensará en el confort de los hombres en la ciudad, en los bienes de consumo sin importar cómo se obtienen, pareciera que el daño es irreversible, el cambio climático es una muestra de ello, los experimentos con animales es otro y la devastación de los bosques fue uno más.

Peter Singer (2003), nos invita a reflexionar sobre la continuidad naturaleza-cultura a partir de comprender la falsa disyuntiva entre animales humanos y no humanos. En una reseña que escribió el señalado autor de un artículo escrito por Stanley y Roslind Godlovitch, y John Harris, sobre el trato a los animales, dice que los autores citados recordaban que las luchas por la liberación del hombre no se ha agotado, que tenemos que ser prudentes para expresar cuáles son las últimas formas de discriminación racial y que la expresión liberación animal "apareció en la prensa por primera vez el 5 de abril de 1973". (p.1). Esta expresión significó que había que considerar la relación entre animales humanos y no humanos. La reflexión de Singer centra su crítica en esta separación pues tiene implicaciones racistas y sexistas, y que por tanto, no podemos seguir haciendo a un lado esta separación entre animales y humanos. Singer (2003), lo expresa así:

A pesar de que la mayor parte de los humanos pueda ser superior en cuanto al razonamiento y otras capacidades intelectuales respecto de los animales no humanos, esto no es suficiente para justificar la línea que hemos trazado entre humanos y animales. Algunos humanos -los niños y quienes tienen severas disfunciones intelectuales- tienen capacidades intelectuales inferiores a las de algunos animales, pero nos sentiríamos escandalizados, y con razón, si alguien propusiera que infligiéramos muertes penosas y lentas a esos humanos intelectualmente inferiores con la finalidad de probar la seguridad de los productos que se compran para el hogar. Tampoco toleraríamos, por supuesto, que se los confinara en jaulas pequeñas y que luego se los carneara para comerlos. El hecho de que estemos preparados para hacer este tipo de cosas a los animales no humanos es entonces signo de "especismo", un prejuicio que sobrevive porque es conveniente para el grupo dominante, en este caso ya no blancos o personas de sexo masculino, sino todos los seres humanos. (p.1).

Justamente esta concepción de separar a los animales, la tierra y el mundo del hombre, y pensar que el futuro está solo en la ciencia y la tecnología, tendrá terribles consecuencias no sólo para los animales y la tierra sino para los humanos. Construir una nueva mirada significa tener un hábitat donde la continuidad naturaleza-cultura, nos permita tejer las relaciones en el cual el sujeto debe ser determinado por la multiplicidad y el igualitarismo zoe, que significa "la fuerza transversal que corta y vuelve a zurcir especies, dominios y categorías precedentemente separadas." (Braidotti, 2015, p.77). La nueva subjetividad, es una responsabilidad relativa fundada en un fuerte sentimiento de colectividad y articulada a la comunidad. Por tanto, es imaginar y crear nuevas relaciones, 
nuevos tejidos que permita la convivencia de los humanos, los animales, la tierra y la ciencia y tecnología.

\section{Conclusión}

La nueva subjetividad es entretejer relaciones entre las dimensiones de los sujetos, la tierra, los animales, la ciencia y tecnología, enfocadas en la mejora de la calidad de vida de los animales y los humanos, de esta manera se podrá demoler la voracidad del capitalismo que ha hecho de cada dimensión un proceso de mercantilización. Este proceso de mercantilización ha sido perfectamente captado para los humanos en relación a los perros y en relación al espacio en que se vive.

Ante esta realidad es necesario generar nuevos planteamientos, horizontes de acción, que desde el ámbito institucional en México pueden surgir como propuestas ante esta problemática social.

La humanización de los perros es una de las tantas secuelas que vivimos actualmente en las ciudades, ante la falta de una reeducación de nuestras prácticas que repercuta en aquellos, así como ante la poca o nula propuesta de generar espacios específicos de acuerdo a sus necesidades, ante estas carencias se muestra como el hombre está envuelto en sí mismo.

\section{Referencias}

Duhua Emilio y Giglia Ángela (2008). Introducción: orden urbano y experiencias metropolitanas, en: las reglas del DESORDEN: habitar la metrópoli. México: UAM-A/siglo veintiuno editores. p. 22

García Ariadna (2013). Hay 35 mil perros callejeros en Xalapa, en: Imagen del Golfo Multimedios S.A. de C.V. http://imagendelgolfo.mx/resumen.php?id=370045 (Consultado 24 junio 2017)

Horkheimer, Max y Adorno, Theodor W. (1997). "CONCEPTO DE ILUMINISMO", en: Dialéctica del iluminismo. México: Editorial Sudamericana. pp 8-33.

http://elsarbresdefahrenheit.net/documentos/ obras/1221/ficheros/horkheimer_y_adorno_dialectica_del_iluminismo.pdf

(Consultado 26 junio 2017)
INEGI (2015). Cuéntame. Información por entidad.. http://cuentame.inegi.org.mx/monografias/informacion/ver/territorio/div municipal.aspx?tema=me (Consultado 28 septiembre 2017)

Levi-Strauss, Claude (1985). “I. Naturaleza y cultura.", en: Las reglas elementales del parentesco (I). México: Origen/ Planeta. Obras Maestras del Pensamiento Contemporáneo. pp. 35-44.

Mayol, Pierre (2010). "Capítulo I. El barrio", en: La invención de lo cotidiano.2. Habitar, cocinar. México: Universidad Iberoamericana-Instituto Tecnológico y Estudios Superiores de Occidente.

Morales Rosalinda (2013). Veracruz es uno de los estados con más perros callejeros en ciudades, en: en: Imagen del Golfo Multimedios S.A. de C.V.

http://imagendelgolfo.mx/resumen.php?id=395822 (Consultado 24 junio 2017)

San Martín Sala, Javier (1999). "1.1. Genealogía del concepto de cultura”, en: Teoría de la cultura. Madrid: Editorial Síntesis. pp. 23-40.

Singer Peter (2003). Liberación animal. Revista The New York Review of Books n 8 del Volumen L, el 15 de mayo de 2003.

http://www.sociales.uba.ar/wp-content/uploads/17.-Liberaci\%C3\%B3n-animal.pdf

(Consultado 25 junio 2017)

http://revistas.uv.mx/index.php/ulua/article/viewFile/1182/pdf

Vera Brizuela (2017). Más de 18 mil perros y gatos callejeros en Xalapa. Revista República de Veracruz, 24 junio 2017. (Consultado 24 junio 2017)

Vergara, Alejandra (2017). Algunas ideas para solucionar el problema de la sobrepoblación canina en México. Revista Letras Libres. Sección Ciencia y Tecnología. 5 de junio de 2017.

http://www.letraslibres.com/espana-mexico/ciencia-y-tecnologia/algunas-ideas-solucionar-el-problema-la-sobrepoblacion-canina-en-mexico

(Consultado 10 junio 2017)

Zamarrón Ismael (2017). CDMX respira media tonelada de materia fecal al día. Periódico Publimetro. 23 de febrero de 2017.

https://www.publimetro.com.mx/mx/ciencia/2017/02/23/cdmx-respira-media-tonelada-materia-fecal-dia.html (Consultado 26 junio 2017)

http://www.fundacion-affinity.org/observatorio https://www.justiciaydefensaanimal.es/ 